\title{
Luzes, câmera... Ação! No ar, a transformação midiática do conceito de periferia no conceito de comunidade ${ }^{1}$
}

\section{Lights, camera...Action! I n the air, the midiactic transformation of the concept of periphery in the concept of community}

\section{Denise da Cruz Paim*}

Pontifícia Universidade Católica do Rio Grande do Sul - PUC-RS, Porto Alegre, Rio Grande do Sul, Brasil

\section{Rodrigo de Oliveira Machado**}

Pontifícia Universidade Católica do Rio Grande do Sul - PUC-RS, Porto Alegre, Rio Grande do Sul, Brasil

\section{Helena B. K. Scarparo***}

Pontifícia Universidade Católica do Rio Grande do Sul - PUC-RS, Porto Alegre, Rio Grande do Sul, Brasil

\section{Adolfo Pizzinato****}

Pontifícia Universidade Católica do Rio Grande do Sul - PUC-RS, Porto Alegre, Rio Grande do Sul, Brasil

\begin{abstract}
RESUMO
Este artigo propõe uma reflexão sobre a construção de uma cultura midiática de periferia e sua relação com o conceito de comunidade, ilustrada pela análise do caso Central da Periferia, programa exibido pela Rede Globo de Televisão, em 2006. Ao problematizar o binômio maioria/minoria e suas consequências na sociedade da informação o estudo busca entender como a construção discursiva do ethos do enunciador da periferia midiática transforma a cultura desse lugar em práticas de consumo.
\end{abstract}

Palavras-chave: Periferia, Mídia, Comunidade, Ethos.

\section{ABSTRACT}

This article proposes a reflection on the construction of a media based culture of the periphery and its relation with the concept of community, illustrated by the analysis in the case of the "Central da Periferia" show, a program produced by the Rede Globo of television, in 2006. To issue the binomial majority/minority and its consequences in the society of information seeks to understand how the discursive construction of the speaker's ethos about the media periphery transforms the culture of this place in consumerism practices.

Keywords: Periphery, Media, Community, Ethos. 


\section{Periferia x comunidade: imagens semelhantes, sentimentos diferentes}

A ampliação significativa do espaço de visibilidade da cultura de periferia na mídia traz indagações sobre a maneira como esse lugar foi se constituindo ao longo do tempo no Brasil, quais seus significados na atualidade e de que forma se interpreta a produção cultural que se distancia dos cânones majoritários. Pensar essas situações, relacionando-as com as formações discursivas da pósmodernidade, provoca estranhamentos principalmente na forma como a cultura da periferia passou a ser entendida e reproduzida na contemporaneidade.

Os processos de urbanização brasileiros, notadamente aqueles efetivados a partir da década de 50 do século $X X$, acarretaram significativas transformações na sociedade. Tal se deveu à industrialização e à modernização das práticas agrárias e foi acirrado pelo projeto desenvolvimentista intensificado nos anos seguintes (DAVIDOVICH, 2000). Tais transformações implicaram o surgimento de inúmeros núcleos de periferia nas grandes cidades. O excesso de pessoas deixando a vida no campo e nas pequenas cidades e a falta de oportunidades de trabalho provocou uma intensa migração rumo às capitais industrializadas. Entre as décadas de 1960 a 1980, período forte do fluxo, cerca de 30 milhões de pessoas se mudaram para os grandes centros urbanos (MARTINE; CAMARGO, 1984).

As várias periferias espalhadas pelo Brasil também ocupam diversos significados no imaginário social da atualidade. Ela não designa apenas o grau de afastamento geográfico do centro urbano. 0 conceito também compreende a distância que a periferia possui do acesso à informação, da vida cívica, dos recursos políticos, sociais, econômicos, e dos padrões idealizados pelos modos de ser chancelados pelos movimentos culturais majoritários. Domingues (1994) argumenta que a periferia "é o lugar da exclusão, da marginalidade e da segregação social, da ausência de uma noção de pertença a um lugar, do déficit de cidadania". Segundo ele, a distância ao centro é uma distância sociológica, simbólica e de poder. Desta forma, a periferia pode, por exemplo, estar localizada no centro geográfico de uma capital e ainda assim ser considerada fora, uma favela, ou uma vila, no contexto gaúcho. Independentemente da maneira como é denominada, Domingues (1994) diz que a periferia se caracteriza pelo afastamento do centro simbólico, ou seja, dos referenciais majoritários dentre de um determinado marco cultural. Esse distanciamento não pode ser medido apenas pela separação real, mas principalmente pela a distância simbólica do "efeito urbano", ou seja, das formas chanceladas pelos modos de ser majoritários na cultura, de como deve ser a vida na cidade. 
O afastamento do efeito urbano, que em muitos casos se traduz em carências econômicas, provocou a construção de outros modos de vida dentro das periferias. Neste âmbito, os movimentos sociais tomam papel de destaque ao implicar diretamente na problematização das questões culturais desses lugares. Eles contribuem para a existência de novas formas de relação social, principalmente ao adotarem estratégias coletivas de mobilização e engajamento. Um dos exemplos dessas iniciativas foi 0 desenvolvimento, a partir dos anos 1970', dos movimentos denominados Sociedade de Amigos do Bairro (SABs) que reunia moradores de determinado local para angariar equipamentos públicos e fomentar a associação de moradores em nome de objetivos comuns (SOUZA, 2003).

A organização social baseada nessa comunhão condiciona a idéia sobre espaço comunitário da periferia na dimensão utópica; ou seja nesse lugar todos se sentem pertencendo a um mesmo grupo. Bauman (2003) ao refletir sobre o conceito de comunidade na atualidade avalia que este traduz noções de segurança, companheirismo, acolhimento e outros pensamentos que fortalecem o ideal paradisíaco da vida comunitária. Trata-se da mesma conotação da discussão realizada em contextos nos quais o atravessamento econômico produz efeitos atenuados na definição de periferia e fortalece a produção de definições associada a características culturais. Entretanto, o próprio Bauman (2003) ponderou que a idealização da comunidade se distancia da realidade vivida no cotidiano, sendo que nesta construção "onírica" a apreensão da liberdade individual e a segregação de outros grupos passam a margem do conceito impregnado no imaginário popular.

A sociedade é composta por uma diversidade de pessoas e grupos culturais, com interesses distintos. Para que prevaleçam os interesses de uns, os de outros acabam sendo sacrificados em nosso modelo predominante de sociedade. De acordo com Moura (1996), esse tipo de relação reforça a demarcação de espaços geográficos e culturais nas cidades. "É na segregação urbana ou segregação espacial que se dá a produção de áreas carentes - periferias urbanas, áreas deterioradas centrais, favelas, cortiços, guetos - e que se contrapõem aos bairros nobres, bem servidos e modernos" (p. 43).

Moura (1996) argumenta que a população da periferia é também formada por uma força de trabalho reserva da indústria, ou seja, pela massa de trabalhadores desempregados, à espera de uma vaga, expulsos pela rotatividade das empresas ou crises sucessivas da economia, mas que também sustentam, mesmo que informalmente, o modelo de sociedade capitalista pós-industrial.

As dificuldades sociais traduzidas na falta de condições para que se exerça o direito à cidadania levam atores sociais da periferia a uma existência insegura de expectativas incertas. Bauman (2003) coloca 
que entre as totalidades imaginárias a que as pessoas acreditavam pertencer e nas quais acreditavam poder encontrar abrigo agora vigora um vazio social. Segundo ele, o Estado já representou esse lugar de conforto, porém, na contemporaneidade, a segurança como todos os aspectos da vida humana num mundo individualizado, é uma tarefa que toca a cada um. "A defesa do lugar, vista da condição necessária de toda segurança, deve ser uma questão do bairro, um assunto comunitário" (p. 102).

Com essa perspectiva os movimentos sociais aparecem em oposição à omissão do poder público. A presença de formas coletivas auxilia na construção da cidadania, tendo como base mobilizatória a percepção das carências comuns. Jacobi (1989) defende que "os movimentos sociais podem ser captados como complexos de relações sociais em que os atores se transformam pela sua interação com os demais". A configuração contemporânea destas relações faz com que o espaço social da periferia produza outro tipo de organização, a comunitária. Ainda que nem sempre conte com todas as comodidades do paradigma do Estado de Bem-Estar (FIORI, 1997). Pela qualidade de suas relações, o espaço social periférico, gradativamente, perde essa configuração (de relação a certo Centro utópico) e desenvolve, com suas próprias potencialidades, um sentimento comunitário que implica numa concepção de comunidade como a desenvolvida por Guareschi (1996). Nessa se constrói um espaço de:

[...] relações igualitárias, que se dão entre pessoas que possuem iguais direitos e deveres. Essas relações implicam que todos possam ter vez e voz, que todos sejam reconhecidos em sua singularidade, onde as diferenças sejam respeitadas. E mais: as relações comunitárias implicam, também, a existência de uma dimensão afetiva, implicam que as pessoas sejam amadas, estimadas e benquistas ( $p$. 97).

Com base nessa definição se evidencia que é na comunidade, e não na periferia, que o sujeito se reconhece pertencente a algum lugar, e é essa posição de pertencimento que cria significados relacionais aos espaços geográficos "periféricos" de antes. A comunidade é um lugar humanamente contraditório por definição: confortável e aconchegante, mesmo que não isento de conflitos ou carências, pois mesmo tais fenômenos, por serem naturalizados dentro do repertório de possibilidades de existência, acabam por ser interpretados como um modelo seguro.

A partir de articulações semelhantes, Bauman (2003) propõe uma reflexão sobre a forma como as comunidades (geograficamente periféricas ou não) estão se organizando na contemporaneidade. Segundo ele o confinamento espacial com o fechamento social acaba misturando proximidade/distância física com a proximidade/distância 
moral. Para o autor essa relação ressalta as diferenças entre os grupos e esses estranhamentos apontam para a exclusão. Ele diz que "a homogeneidade dos de dentro entra em contraste com a heterogeneidade dos de fora" (p.105).

Essa distinção aproxima a discussão da relação entre maioria/minoria. Tais dispositivos implicam uma divisão social que materializa regras de ação dos atores sociais. Desse modo, se produzem discursos que cristalizam os modos de ser, pensar e viver dos sujeitos. Trata-se de um padrão de relação micropolítica que pode ser associado ao binômio maioria/minoria, no qual a maioria supera a minoria no controle dos recursos econômicos, de status e de poder. Estabelece, assim, relações de dominação com as minorias sociais.

Montero (2003) define as condições de maioria e minoria nos grupos sociais, não em função do critério numérico de membros, mas a partir do poder que exerce um determinado grupo:

“[...] mayoría es la que detene y ejerce el poder, com independencia de su número. Minoría es el grupo al cual se priva del ejercicio de determinados poderes, o se impide su acceso a las condiciones para adquirirlos" (p. 120).

A concepção de Montero se apóia na perspectiva de Moscovici (1981), que rompe com a idéia de ação unilateral de mudança, na qual as maiorias se constituem como postulantes das mudanças e as minorias têm o papel passivo de depositários do desejo majoritário. O autor propõe que as minorias participam como propulsores das mudanças, carregando em si o potencial de estabelecer novas idéias e comportamentos.

Em seu conceito de minorias ativas, Moscovici (1981) apresenta os participantes destas como sujeitos possuidores de uma visão e proposta alternativa a sociedade majoritária. Moscovici (1981) ressalta que ambas, maioria e minoria, provocam mudanças, porém enquanto a maioria atinge o seu objetivo através da simples aceitação dos seus postulados, as minorias provocam mudanças mais profundas ao conseguir que as pessoas mudem as suas opiniões, convertendo-os de suas premissas iniciais. São as maiorias que estabelecem os discursos que devem circular em um campo social. São elas que criam os significados dos enunciados, determinam seu sentido e definem as verdades. Desse modo, tais significados não podem obviar uma conotação valorativa, seja ela qual for (GUARESCHI, 1996).

Essa valoração social, opera no sentido de produzir jogos de verdade que naturalizem as diferenças entre os grupos sociais, através de mecanismos de estereotipificação. Hall (1997) entende que estereotipar é um mecanismo psicossocial da manutenção da ordem 
social e simbólica, pois estabelece uma fronteira entre o "normal" e o desviante, o normal e o patológico, o aceitável e o inaceitável, o que pertence e $o$ que não pertence, 0 nós e o eles. $O$ autor saliente que estereotipar reduz, essencializa, naturaliza e conserta as diferenças, excluindo ou expelindo tudo aquilo que não se enquadra.

Os estereótipos criam e sustentam as relações de dominação que estão presentes nas sociedades nas mais variadas formas. Entre elas pode-se citar a dominação econômica, política, cultural, de raças, institucional, patriarcal, entre tantas outras existentes nos mais diversos meios (GUARESCHI, 1996). Autores como Mead (1934/1989), defenderam a idéia de que é a interiorização do "outro generalizado" que constitui o núcleo da identidade. Nele se encontram os papéis representados nos diferentes contextos sociais e culturais que influenciaram teorias psicossociais posteriores. Para Tajfel (1981), por exemplo, a identidade social pode ser produto do sentido de pertença a um grupo. Identificar-se com um grupo significa categorizar, diferenciar os de dentro (nós) dos de fora (eles). Portanto a definição que fazemos de nós depende daquilo que consideramos que nos diferencia dos demais. Mas o contrário também vale a definição que fazemos dos outros depende do que os diferencia de nós, ou do que nós os atribuímos ao nos diferenciarmos deles.

Importante salientar novamente que os termos maioria e minoria, presentes neste texto, não são tomados pelos aspetos numéricos, mas em relação ao controle e a dominação que um grupo exerce sobre o outro. O termo minoria deve ser entendido em seu sentido sócio-antropológico que articula essa noção ao grupo excluído das bases hegemônicas para limites identificatórios. Referem-se a segmentos da sociedade que possuem traços ou práticas culturais específicas e que, por isso, são desvalorizados e não plenamente integrados na cultura legitimada pela maioria. A maneira como é confrontada essa diferenciação torna explícito o tom de preconceito e discriminação que ecoa na sociedade colocando as minorias em desigualdade de direitos e oportunidades. Em razão disso, as minorias muitas vezes, reproduzem tal posição e se reconhecem como um grupo sem autonomia, responsabilidade, confiança e não se identificam nos sistemas existentes de poder e crença. Moscovici (2000, p. 77), por exemplo, afirma que: "quando um grupo minoritário deseja introduzir um elemento novo, perturbador em um grupo, ele carece de poder e, às vezes, da competência necessária para impor seu ponto de vista a uma população de maior importância". Desta forma, a sociedade é construída através de sujeitos que reproduzem as determinações de uma maioria. Contestar o andamento desse processo coloca o indivíduo na posição de desviante, mal adaptado ou marginal.

Ao abandonar a idéia de que a cultura do "centro" (da maioria) deveria ser entendida como parâmetro único dos modos de ser da 
"periferia" (minoria) passou-se a observar o potencial de criação cultural periférica, nas vivências comunitárias. Prysthon (2003) argumenta que a produção cultural da periferia constituiu a nova tendência na teoria crítica, onde a cultura dá origem a uma nova moldura conceitual que afeta a própria idéia de periferia. Para ela, o descentramento ocasiona uma inversão de valores, na qual o centro passa a fazer parte da periferia e a periferia do centro, em uma perspectiva multicultural (não necessariamente multiétnica) menos polarizada. Tal perspectiva pode ser definida como uma dinâmica, que permite conceber que a cultura periférica não passe a ser percebida apenas pela cultura central, mas também seja consumida pelos grupos majoritários/centrais, ainda que com significados diferentes daqueles que o grupo minoritário dá a essas práticas de produção e consumo cultural.

A efervescência cultural que movimenta a interpretação cultural da periferia despertou o interesse dos meios de comunicação de massa. A busca por novos produtos midiáticos levou os olhares dos produtores de televisão, rádio e jornais a fixarem a atenção nas criações que estavam acontecendo longe dos centros urbanos.

O processo de midiatização da cultura da periferia, para além do sentimento de pertencimento comunitário, apresenta os modos de vida de seus habitantes e produz uma nova prática de consumo cultural no país. Bentes (2006) denominou essa tendência de "periferia legal" onde existe uma leitura idealizada onde se minimizam os processos de exclusão, violência e preconceito. A "Periferia Legal", amplamente divulgada pelos meios de comunicação, aborda a cultura periférica de uma maneira atraente e até glamourosa. A realidade observada através da televisão torna-se mais interessante do que a vista pela janela da sala, despertando novos desejos e construindo novas possibilidades de ser.

Sendo assim, para entender a maneira como este processo de "glamorização" se constitui deve-se primeiro entender os sentidos produzidos pelo termo comunidade para os sujeitos em uma sociedade. Colocando de outra forma: evidenciar o ethos (ou seja: adesão dos sujeitos a certa posição discursiva) que esse espaço organiza em um grupo social.

Associar o conceito de comunidade à realidade das periferias, mais do que aproximar, evidencia uma relação de distância entre os termos que, originalmente separados, figuram no discurso midiático em contraditória substituição. Na atualidade o que se percebe é a substituição de um termo pelo outro, tratados midiaticamente como se fossem equivalentes e forçando a ressignificação estereotipada de um pelo outro. Entender as diferenças e aproximações entre esses conceitos auxilia na investigação sobre a forma como o ethos da periferia midiática se organiza. 


\section{Ethos midiático da periferia: a reconstrução de um conceito}

Toda reflexão sobre a sociedade pós-moderna exige um entendimento sobre os meios de comunicação. Isso se deve ao fato de que na contemporaneidade, as mudanças sociais estão predominantemente assentadas nas transformações vivenciadas e provocadas pela mídia. O fluxo das informações e seu impacto sobre os sujeitos produzem reorganizações na vida social.

No século passado, essa nova ordem experimentada na atualidade, foi descrita criticamente pelos teóricos da Escola de Frankfurt. Fundado na década de 20 , essa instituição dedicava-se à pesquisa social tendo entre seus filósofos Horkheimer, Adorno, Benjamin, Marcuse e Habermas. Pioneiros nas discussões sobre cultura e meios de comunicação, esses pensadores conceituaram a disseminação da macrocultura pós-moderna como "indústria cultural".

Para tais pensadores, a transformação da cultura em mercadoria, processo que se desenvolve no capitalismo tardio, prejudica a singularidade dos indivíduos e as características culturais específicas de cada grupo. A mídia é importante ferramenta para a divulgação de novos hábitos e para a consolidação daqueles hábitos e formas de ser, desejados pela maioria. Os pensadores de Frankfurt entendiam os meios de comunicação como tradutores, fiadores das produções de vanguarda, se apropriando do que poderia ser uma criação, um avanço cultural.

Rüdger (2004) sintetiza o pensamento desses teóricos, definindo produção cultural não mais como sinônimo de criações artísticas e literárias, mas englobando todo o conjunto da atividade econômica. $\mathrm{Na}$ atualidade, a tendência é legitimar as culturas de massa e saudar a auto proclamada sociedade da informação. Através dos avanços tecnológicos, os meios de comunicação proporcionam uma verdadeira revolução nas interações sociais. A derrubada de fronteiras e aproximação de mundos levou a humanidade a uma troca de informações alterando a noção de pertencimento e de poder.

$\mathrm{Na}$ sociedade da informação, o conhecimento é considerado um recurso estratégico de agregação de valor, transformável em mercadoria e, portanto, hierarquicamente categorizável. Ele pode tanto ser fator de dominação quanto de emancipação. A partir disso é possível compreender os discursos produzidos nestes meios como importantes agentes de subjetivação dos indivíduos do corpo social. Os processos de subjetivação podem ser entendidos como práticas de constituição do sujeito, ou seja, na relação com as pessoas, discursos, objetos e estruturas sociais através da história. "Em um sentido amplo, Foucault fala dos modos de subjetivação como modos de objetivação do sujeito, isto é, modos em que o sujeito aparece 
como objeto de uma determinada relação de conhecimento e de poder" (CASTRO, 2009, p. 408).

O grande volume de circulação das informações em nossa sociedade, possibilitada pelos inúmeros meios tecnológicos, faz com que chegue até os sujeitos mensagens com os mais diferentes conteúdos, complexificando os processos de subjetivação. Essas "informações estão carregadas de estilos de vida, visão de mundo, ideologias, valores e contravalores. Seus conteúdos estão sempre direcionados por interesses humanos, geralmente em proveito dos grupos que controlam essas informações" (Sánchez, 1997, p. 40-41).

Os meios de comunicação definem os assuntos que entrarão em circulação em uma sociedade, o que faz com que Bertrand (1999) afirme que ninguém possui um conhecimento direto do conjunto do globo. Além das experiências pessoais, o que se sabe provém das ferramentas (legitimadas ou não) de produção cultural, dentre as quais se destaca a mídia. Para a maioria das pessoas, os assuntos dos quais a mídia não fala, não existem.

Para o autor, a mídia determina a ordem do dia da sociedade, porém ela não dita o que as pessoas devem pensar, mas decide no que elas vão pensar. Desta forma, o discurso midiático pode ser entendido como uma tecnologia de poder, pois gera sistemas de correlações de força e efeitos de verdade. Ele participa da formação da opinião, modifica valores e identidades. Através dos discursos da mídia, o sujeito estabelece contato com outros estilos de vida. Ao confrontar com essa diversidade sociocultural, ele é apresentado a uma nova realidade que poderá operar na construção da sua identidade, pois ao mesmo tempo em que a mídia individualiza modos de vida e comportamento, ela aproxima mundos distintos unindo esses sentimentos isolados e transformando-os em sentidos coletivos.

\footnotetext{
[...] uma sociedade como a nossa, mas no fundo em qualquer sociedade, existem relações de poder múltiplas que atravessam, caracterizam e constituem o corpo social e que estas relações de poder não podem se dissociar, se estabelecer nem funcionar sem uma produção, uma acumulação, uma circulação e um funcionamento do discurso (FOUCAULT, 1992, p. 179-180).
}

A discursividade sustenta os saberes em circulação em uma determinada época. As condições que permitem o aparecimento de certos enunciados e a proibição de outros são estratégias que controlam os sentidos e as verdades. No livro A arqueologia do saber, Foucault (1995) define a produção do discurso como controlada, selecionada, organizada e redistribuída por procedimentos que visam determinar aquilo que pode ser dito em certo momento. Entendendo - discurso como prática culturalmente significativa, Foucault estabelece uma estreita relação entre dizeres e fazeres. Para ele, as 
práticas discursivas materializam as ações dos sujeitos na história. Desta forma, as práticas sociais se constituem discursivamente e analisar discursos significa tentar compreender a maneira como as verdades são produzidas e enunciadas.

A mídia constitui o principal recurso social discursivo em nossos dias. Ela narra ações e destaca os fatos. A regulação do saber, exercida pelos meios de comunicação, afeta o comportamento das pessoas. 0 conteúdo dos textos midiáticos é disponibilizado em diversos meios de comunicação. A televisão é apenas uma delas. O rádio, o jornal, as revistas, o cinema e a internet são outros canais disponíveis para a transmissão dessas mensagens. Gregolin (2007) analisa que: "o que os textos da mídia oferecem não é a realidade, mas uma construção que permite ao leitor produzir formas simbólicas de representação da sua relação com a realidade concreta" (p. 16).

A produção dos textos e discursos midiáticos obedece à lógica do mercado e, como mercadoria em um mundo globalizado, deve reinventar-se a todo o momento. A mídia de entretenimento pode ser considerada como a mais fluída. É através dela que os canais de comunicação conseguem atingir altos índices de audiência. Os veículos que utilizam a programação para o divertimento, à distração e ao passatempo estão constantemente em busca de novas atrações para prender a atenção das pessoas.

Independentemente de seu posicionamento explícito, a esfera da diversão midiática desempenha cada vez mais um papel de agente de mudança na sociedade, pois potencialmente gera modelos de sociedade, não mais alicerçados exclusivamente no desenvolvimento das forças produtivas, mas no desenvolvimento do consumo (MARIN, 2009).

Nesse movimento, novos produtos midiáticos são postos nas grades de programação para a apreciação da população. Os departamentos artísticos das emissoras - onde as atrações são criadas e elaboradas - estão constantemente experimentando novas fórmulas. Como já previra Lipovetsky (2004), a capacidade da mídia de criar, em grande escala, fenômenos culturais se expressa em best-sellers, em hits, na idolatria de stars na adesão às modas, no sucesso do mês, que mesmo fugaz, tende a homogeneizar-se nos discursos sociais.

$\mathrm{Na}$ esteira recente dessa capacidade produtiva midiática estão os reality shows, por exemplo. Surgidos nos primeiros anos do século $X X I$, esses programas conquistaram a simpatia dos brasileiros e a "vida real" passou a ser retratada na tela da televisão. A partir dessa experiência, onde a realidade se mistura com a ficção, um novo fenômeno comunicativo surge na sociedade. Vilches (1996) acredita que a maior mudança aconteceu entre a forma de fazer e a forma de olhar a televisão. Anônimos passam de simples espectadores para protagonistas de um programa exibido em rede nacional. Essa espetacularização do cotidiano gera uma identificação do indivíduo 
com o participante, legitimando assim esse tipo de programação e (re)validando o veículo de comunicação como legitimador dos modos de ser. Através da falsa vitrine dos reality, os meios de comunicação (em uma perspectiva ingênua) retratam a realidade existente e, ao mesmo tempo, a constroem. Celebridades midiáticas nascem "do nada", sem dom artístico ou de beleza; saem do anonimato e se caracterizam por serem sujeitos comuns, vindos "do povo". "O mundo passa a ser um grande cenário, pois a simples presença de uma câmera e alguns focos de luz faz com que as pessoas passem a sentir-se atores, intérpretes de sua própria história" (CASTRO, 2006, p. 53).

Esse encantamento pelo mundo mediado engendra uma idolatria/ glamourização de coisas e pessoas. O universo ganha um novo valor quando exibido nos meios de comunicação. Neste sentido há um acréscimo de gêneros audiovisuais em nossas narrativas vitais. Os gestos cotidianos mais insignificantes tendem a aproximar-se às cenas dos videoclips e das publicidades (SIBILIA, 2008).

Nesta cultura das aparências, de consumo e do espetáculo, os fatos dos dia-a-dia são expostos como sinônimo de criatividade e autenticidade. Nesse novo contexto, a vida real é transmitida, pelos mais diversos dispositivos de comunicação, com a intenção de tornarse alguém no mundo mediado. A cultura mediatizada começa a estruturar-se em uma perspectiva audiovisual, onde as "telas" (computador, televisão, celular, câmera de fotos) "expandem o campo de visibilidade, esse espaço onde cada um pode se construir como uma subjetividade alterdirigida. A profusão de telas multiplica ao infinito as possibilidades de se exibir diante dos olhares alheios e, desse modo, tornar-se um eu visível" (SIBILIA, 2008, p. 111).

Em uma sociedade espetacularizada, a realidade transforma-se em entretenimento e as subjetividades modernas se arquitetam a partir do encontro constante do cotidiano com a ficção. Debord (1995) afirmava, já em 1967, que: “toda a vida das sociedades nas quais reinam as condições modernas de produção se anuncia como uma imensa acumulação de espetáculos. Tudo o que era diretamente vivido se esvai na fumaça da representação" (p. 13).

Ao fazer do cotidiano conteúdo para abastecer a programação, os meios de comunicação dão condições para que diferentes modos de vida entrem em circulação em uma sociedade. Na atualidade essa é a principal maneira de se trocar experiências. Os sujeitos compartilham significados que servem para codificar, organizar e regular a conduta uns em relação aos outros. A interpretação dessas ações dá forma tanto para aqueles que a praticam quanto para os que a observam. Desta maneira, os variados sistemas de significado constituem as culturas existentes em uma organização social.

Para Hall (1997) a cultura tem assumido uma função de importância sem igual no que diz respeito à estrutura de uma sociedade. Ele 
afirma que a cultura está na base dos processos de desenvolvimento global. "Os meios de produção, circulação e troca cultural, em particular, têm se expandido, através das tecnologias e da revolução da informação" (p. 17).

A partir disso, pensar as identidades sociais, construídas pelos discursos vigentes em uma sociedade, é refletir sobre sua formação através da cultura e não fora dela. Hall (1997) entende que as identidades são o resultado de uma identificação que permite um posicionamento no interior das definições que os discursos culturais fornecem ou que subjetivam os sujeitos. Segundo ele, a análise social contemporânea passou a ver a cultura como uma condição constitutiva da vida social, ao invés de uma variável dependente, provocando, assim, uma mudança de paradigma nas ciências sociais e nas humanidades.

Esse movimento foi chamado de "virada cultural". Uma ação que iniciou com uma revolução de atitudes. Uma delas diz respeito à questão das linguagens que passaram a ser percebidas como práticas de representação na construção e circulação do significado/sentido. A partir desse momento, a relação entre a linguagem e os objetos descritos por ela foram revistos. A linguagem passou a ser entendida como constitutiva dos fatos e não como algo que apenas os relata. Trata-se de uma relação direta entre linguagem e o que se denomina "realidade". Dentro dessa perspectiva, os significados surgem não das coisas em si (realidade), "mas a partir dos jogos da linguagem e dos sistemas de classificação nos quais as coisas são inseridas. O que consideramos fatos naturais são, portanto, também fenômenos discursivos" (HALL, 1997, p. 29).

Dar a cultura um papel constitutivo e determinado na compreensão e na análise de todas as instituições e relações sociais é diferente da forma como a mesma foi teorizada por vários anos. Para muitos autores, a virada cultural é vista como uma reconfiguração de elementos com foco na linguagem e na cultura como área substantiva e não mais como algo que servia de integração para o restante do sistema social.

A partir desses conceitos, que compreendem a cultura por meio da análise do discurso, surge à problemática do ethos ligado a uma conceituação enunciativa. A idéia de que ao falar um locutor ativa em seus destinatários uma representação de si mesmo tem despertado interesse por se tratar de uma evolução na observação da palavra publicamente proferida, principalmente nos meios de comunicação. A noção do ethos pressupõe instâncias de subjetividade tanto na produção quanto na recepção do discurso.

De acordo com Maingueneau (2008), Aristóteles foi o primeiro autor a elaborar um conceito sobre o ethos. Ele pretendia apresentar uma técnica cujo objetivo não era examinar o que é persuasivo para tal ou qual indivíduo, mas para tal ou qual tipo de indivíduos. Gibert (no 
século XVIII) resumiu em um triângulo a retórica antiga: “instruímos com argumentos; movemos pelas paixões; insinuamos com os costumes: os "argumentos" correspondem ao logos, as "paixões", ao pathos, os "costumes" ao ethos" (MAINGUENEAU, 2008, p. 57).

I mportante reforçar que o ethos está ligado à própria enunciação. É através do discurso que se confere credibilidade ao orador. A função do ethos é a de causar impacto pela forma como se constrói o discurso, a dar uma imagem de si capaz de convencer a audiência, ganhando sua confiança. O destinatário deve, então, atribuir certas propriedades à instância que é posta como fonte do acontecimento enunciativo (MAINGUENEAU, 2008).

O ethos mobiliza tudo o que, na enunciação discursiva, contribui para emitir uma imagem do orador destinada ao auditório. Essa imagem não é estática e completamente delimitada, mas, do próprio movimento da fala do locutor. "O ethos não age no primeiro plano, mas de forma lateral. Ele implica uma experiência sensível do discurso, mobiliza a afetividade do destinatário" (MAINGUENEAU, 2008, p. 57).

Por meio do ethos, o destinatário está convocado a um lugar, inscrito na cena de enunciação que o texto implica. Para Maingueneau (2008) essa cena de enunciação se compõe de três cenas, que ele chamou de "cena englobante", "cena genérica" e "cenografia". Essa noção geral da cena atribui ao discurso um estatuto pragmático, ela o integra em um gênero: publicitário, administrativo, filosófico.

\begin{abstract}
"A cena genérica é do contrato associado a um gênero ou a um subgênero do discurso: o editorial, o sermão, o guia turístico, a consulta médica... Quanto à cenografia, ela não é imposta pelo gênero, mas construída pelo próprio texto: um sermão pode ser anunciado por meio de uma cenografia professoral, profética, amigável" (MAINGUENEAU, 2008, p. 70).
\end{abstract}

Sendo assim, a cenografia não deve ser compreendida como um quadro, um ambiente, como se o discurso ocorresse em um espaço já construído. A cenografia é a cena da fala que o discurso pressupõe para poder ser enunciado. "Todo discurso pretende instituir a situação de enunciação que o torna pertinente" (MAINGUENEAU, 2008, p. 70). Para o teórico francês a noção do ethos permite refletir sobre o processo mais geral da adesão dos sujeitos a determinado posicionamento. Enquanto a concepção aristotélica do ethos está mais ligada à oralidade, aqui se propõe que todo texto tem uma vocalidade específica que não recobre somente a dimensão verbal, mas também o conjunto das determinações físicas e psíquicas associadas ao "fiador" pelas representações sociais coletivas. Essa vocalidade permite relacioná-la a uma caracterização do corpo do 
enunciador a um "fiador" que, por meio do seu "tom", atesta o que é dito.

Assim, acaba-se por atribuir ao fiador um "caráter" e uma "corporalidade", cujo grau de precisão altera de acordo com o texto. A identificação do destinatário com o fiador permite o acesso a um mundo ético, ativado por meio da leitura e que é um estereótipo cultural que inclui determinado número de situações estereotípicas associadas a comportamentos. A publicidade contemporânea apóia-se muito em tais estereótipos (o mundo ético dos executivos, dos esnobes, das estrelas de cinema, etc.) (MAINGUENEAU, 2008).

A noção de ethos possui um interesse essencialmente prático, e não claramente teórico.

\footnotetext{
“Em nossa prática ordinária de fala, o ethos responde a questões empíricas efetivas, relativas a uma zona íntima e pouco explorada de nossa relação com a linguagem, nas quais nossa identificação é tal que se estabelecem estratégias de proteção" (MAINGUENEAU, 2008, p. 73).
}

Desta forma, a especificidade de um ethos remete a figura de um "fiador" que por meio de sua fala, se dá uma identidade em acordo com o mundo que ele supostamente faz surgir. Tal problemática do ethos leva a contestar a redução da interpretação a uma simples decodificação, alguma coisa da ordem da experiência sensível funciona no processo de comunicação verbal. Para Maingueneau (2008) as "idéias" suscitam a adesão do leitor por meio de uma maneira de dizer que é também uma maneira de ser.

Esse processo é especialmente importante quando se analisa a transformação midiática do conceito de periferia no de comunidade, onde o papel do fiador e a configuração do ethos determinam que a mesma configuração geográfico-econômica que provoca o mal-estar dos (tele)diários e programas sensacionalistas de caráter policial pode ser transformado em produto de consumo do tipo entretenimento.

\section{A periferia vendida}

Na última década o grande interesse dos meios de comunicação pela temática "periferia" motivou a produção de filmes, seriados e programas. Somente a Rede Globo de televisão, nos últimos seis anos, é responsável pela exibição de quatro produções que abordaram esse tema: a série Cidade dos homens (2002 e 2005), o programa Central da Periferia (2006), a minissérie Antônia (2006) e o documentário Falcão - Meninos do Tráfico (2006). Além disso, a novela Duas Caras (2007), exibida em horário nobre na emissora, 
trouxe aos telespectadores o cotidiano de uma favela do Rio de Janeiro.

Outras redes de televisão também perceberam esse movimento em direção à periferia. A Rede Record apresentou com pioneirismo um programa feito por alguém da periferia para a periferia. O programa Domingo da Gente (2004), era apresentado por Netinho de Paula e tinha como ponto alto da atração o quadro "A Princesa e o Plebeu"2. Após um desacordo comercial, o programa e o quadro passaram a ser apresentados na emissora SBT com o nome de Show da Gente (2009). Também na Rede Record de Televisão, a novela Vidas Opostas (2006) alcançou surpreendentes números de audiência mostrando o dia-a-dia de uma comunidade da periferia carioca. Essa produção ganhou diversas premiações inclusive o Prêmio Qualidade Brasil $^{3}$, em 2007. Nos cinemas ainda pode-se citar filmes como Cidade de Deus (2002), Ônibus 174 (2002), Tropa de Elite I e II (2007 e 2010), entre outros.

Em todas essas produções a periferia cultural estava posta como protagonista colocando em cheque evidente essa mesma definição. A forma como essas histórias foram articuladas imprimiram repetidas abordagens sobre a problemática social da desassistência como causadora da violência, miséria e exclusão. A exceção nessa tendência foi o programa Central da Periferia que apresentava um recorte cultural dos subúrbios brasileiros. Através dessa atração a apresentadora Regina Casé assumia como pesquisadora de campo e ia às diversas periferias do país em busca do seu objeto de análise: os marcadores culturais/identitários de cada lugar.

O programa foi criado pela apresentadora Regina Casé, pelo antropólogo Hermano Vianna e pelo diretor Guel Arraes. Ele estreou no dia 8 de abril de 2006 e foi exibido, até o dia 23 de dezembro do mesmo ano, sempre no primeiro sábado de cada mês, com uma hora de duração. Gravado em favelas, as culturas das periferias foram o foco principal deste programa de auditório ao ar livre. Comunidades pobres ganharam espaço e visibilidade nacional para mostrar suas próprias atrações e modos de ser, teoricamente, desconhecidos do público majoritário brasileiro. A idéia era colocar em debate a nova relação entre as produções culturais do/no centro e da/na periferia no país. O nome da atração já foi um convite ao debate.

Um manifesto divulgado por Vianna ([2006]), no lançamento do programa, afirmava que a população urbana do mundo já é maior que toda a população do planeta em 1960. Segundo Vianna, o número de habitantes das grandes cidades cresceu vertiginosamente em um período em que a economia da maioria dos centros urbanos estava estagnada. Como a migração para as cidades não parou, calcula-se que mais de um bilhão de pessoas vivam na periferia dos grandes centros urbanos de todos os países. 
Durante todo o ano de 2006, foram produzidas oito edições, gravadas em diferentes estados do país. Central da Periferia incluía também imagens dos bastidores do show e reportagens especiais, realizadas pela apresentadora Regina Casé, que visitava a casa de seus convidados ou mesmo projetos sociais bem-sucedidos das periferias. Nas palavras de seu idealizador, o programa não quer falar por esses ídolos e projetos periféricos, mas sim abrir espaço para amplificar as múltiplas vozes das periferias, para que elas conversem finalmente com o Brasil inteiro. "Você não precisa gostar de nada que o "Central da Periferia" vai mostrar. Você só não pode ignorar que isso tudo está acontecendo" ([VIANNA, 2006, p. 03]).

Paralelamente, foi lançada a série de entrevistas Minha Periferia que foi transmitida todos os domingos entre os dias 23 de julho e 24 de dezembro, com inserções de 6 a 12 minutos, como um quadro do programa Fantástico, da Rede Globo. Nessas entrevistas a apresentadora Regina Casé abordava as temáticas da cultura da periferia brasileira, a divulgação de seus produtos e a representação social dos moradores de favela.

Em 09 de setembro de 2007, estreou - no programa Fantástico - a série de 16 reportagens Central da periferia - Minha periferia é o mundo. A série, resultado das viagens internacionais de Regina Casé para lugares como a Cidade do México, Luanda (Angola) e os subúrbios de Paris (França), mostra como as práticas culturais das periferias brasileiras são percebidas nas periferias do mundo.

O conjunto de obras expressas acima e este fenômeno de midatização da cultura produzida na periferia aponta para o desejo dos meios de comunicação de (re)significar os marcadores desse lugar. É possível identificar no projeto Central da Periferia uma busca para publicizar a favela como um lugar de pertencimento para seus moradores. Apesar das dificuldades, os sujeitos que residem na periferia constroem maneiras de se sentir em comunidade.

As interações cotidianas veiculadas no programa da Rede Globo sugerem um olhar para os dispositivos que provocam essa maneira de pensar a cultura da periferia. Ao relacionar esse entendimento de periferia/comunidade com as práticas de consumo, tão presente na contemporaneidade, percebe-se que, mais do que pensar em uma possibilidade social, os meios de comunicação visam transformar os modos de ser da periferia em mercadoria para colocá-la à venda na grade de sua programação. A necessidade de fazer com que os sujeitos deste lugar se reconheçam na tela da televisão é uma maneira de aproximar este público com a emissora e, conseqüentemente, conquistar mais audiência. O resultado dessa estratégia são novos "clientes" para os espaços comerciais interessados em vender seus produtos para os consumidores da periferia. 
O próprio slogan da emissora: "Globo a gente se vê por aqui" fortalece esse pensamento de encontro, reunião, conjunto, mas, principalmente, essa frase remete a uma idéia que os iguais se enxergam naquela programação. Tornando o sujeito que assiste aos programas da emissora, identificado com aquele universo, portanto pertencente à comunidade da Rede Globo.

Apresentar a "periferia legal" mais do que mostrar um lado otimista e criativo da favela é um esforço para salientar que esse espaço, quando transformado em comunidade, os sentimentos de proteção, segurança e pertencimento amenizam as mazelas vivenciadas no diaa-dia. O estar, ou ao menos sentir-se, em grupo torna-se mais agradável e simpático aos olhos de quem vê e de quem vive a realidade das periferias.

Ao lançar a visão de Moscovici (1980) sobre a dinâmica maioria/minoria pode-se elencar que a presença do discurso pacificador dessas periferias, e o viés do foco, sobretudo, em características positivas, têm como função promover a aceitação dos locais e das pessoas que neles residem perante o restante da sociedade.

Sendo assim, o "Central da Periferia" abriu espaço para mostrar, dentro do enquadramento do programa, o contraste com as demais representações midiáticas desse lugar. Se os telejornais apresentam o lado do abandono, da violência, do crime nas favelas, o programa comandado por Regina Casé quis mostrar que se existe o abandono, também existe a solidariedade. Se existe o criminoso, também existe o trabalhador, mas principalmente, se existe um centro é porque também existe uma periferia que merece ser olhada e reconhecida em sua totalidade não apenas pelo lado de exclusão e dos problemas sociais. Pensar a periferia a partir de outra lógica organiza um ethos diferente de um mesmo lugar. Através dessa possibilidade a favela deixa de ser "periferia" e se transforma em "comunidade". Neste ponto se encontra a busca de conciliar as comunidades retratadas ao ideal utópico, conforme proposto por Bauman, na qual o cuidado com o outro predomina e os interesses individuais desaparecem.

\section{Considerações finais}

Ao analisarmos a construção midiática do conceito de comunidade, na relação com o conceito de periferia, verifica-se a importância de desenvolver estudos, pautados no uso dos aportes da Psicologia Social, que favorecessem críticas das práticas sociais contemporâneas. Tais práticas se desenham nas dinâmicas da complexidade dos modos de relação/comunicação humanas atuais. Nesse sentido, a aproximação, confrontação e análise dos conceitos de periferia e comunidade mostram movimentos de tensionamento e 
flexibilização das fronteiras conceituais que traduzem transformação das expectativas sociais em função da diversidade de experiências humanas presentes, mas nem sempre anunciadas, na sociedade brasileira. Resta compreender ainda, o não-dito ou não visibilizado pela mídia, uma vez que os Editoriais midiáticos suportam um limite de diversidade que não da conta da/s realidade/s.

\section{Referências}

BAUMAN, Z. Comunidade: a busca por segurança no mundo atual. Tradução, Plínio Dentzien. Rio de Janeiro: Jorge Zahar, 2003.

BENTES, I. O contraditório discurso da TV sobre a periferia, entrevista concedida:MELO, Dafne. Portal Brasil de Fato. Disponível em: <http://www.brasildefato.com.br/v01/agencia/entrevistas/aperiferia-como-convem > Acessado em: 10 jun. 2009

BERTRAND, C. A deontologia das mídias. Bauru: EDUSC, 1999. CASTRO, C. Por que os reality shows conquistam audiências? São Paulo: Paulus, 2006.

CASTRO, E. Vocabulário de Foucault: um percurso pelos seus temas, conceitos e autores. Belo Horizonte: Autêntica, 2009. DAVIDOVICH, F. A questão urbana. In: I BGE. Atlas Nacional do Brasil. Rio de Janeiro: 2000.

DEBORD, G. La sociedad del espectáculo. Buenos Aires: La Marca, 1995.

DOMINGUES, A. (Sub)úrbios e (sub)urbanos: o mal estar da periferia ou a mistificação dos conceitos? Revista da Faculdade de Letras Geografia I Série. Porto, vol. 10/11, p. 5-18, 1994. Disponível em: <http://ler.letras.up.pt/uploads/ficheiros/1588.pdf>. Acesso em: 19 set. 2009.

FIORI, J. Estado de bem-estar social: padrões e crises. PHYSIS: Revista de Saúde Coletiva, Rio de Janeiro, v.7, n.2, p. 129-147, 1997.

FOUCAULT, M. A arqueologia do saber. 4. ed. Rio de Janeiro: Forense Universitária, 1995.

Microfísica do poder. Rio de Janeiro: Graal, 1992.

GREGOLIN, M. R. Análise do discurso e mídia: a (re)produção de identidades. Revista Comunicação, Mídia e Consumo, São Paulo, v.4, n.11, p. 11-25, nov. 2007.

GOULART, F. A. A. Representações sociais, ação política e cidadania. Cadernos de Saúde Pública, Rio de Janeiro, v. 9, n. 4, p. 477-486 out./dez., 1993.

GUARESCHI, P. Psicologia Social Comunitária: da solidariedade à autonomia. Rio de Janeiro: Vozes, 1996. 
HALL, S. The spectable of the "other". In: HALL, S. (Ed.). Representation. Culture representations and signifying practices. London: Sage - The Open University, 1997.

JACOBI, P. Movimentos sociais e políticas públicas. São Paulo: Cortez, 1989.

LI POVETSKY, G. Metamoforses da cultura liberal: ética, mídia e empresa. Porto Alegre: Sulina, 2004.

MAI NGUENEAU, D. Cenas da enunciação. Organização Sírio Posseti, Maria Cecília Pérez de Souza-e-Silva. São Paulo: Parábola Editorial, 2008.

MARIN, E. C. Entretenimento: uma mercadoria com valor em alta. Revista Movimento, Porto Alegre, v.15, n.2, abr./jun. 2009.

MARTINE, G.; CAMARGO, J. L. Crescimento e distribuição da população brasileira: tendências recentes. Revista Brasileira de Estudos de População, Rio de Janeiro, v. 1, n. 3, 1984.

$M E A D, G$. H. Mind, self and society from the standpoint of a social behaviourist. Chicago: University of Chicago Press, 1934/1989.

MONTERO, M. Teoria y práctica de la psicologia comunitária: la tensión entre comunidade y sociedad. 1. ed. Buenos Aires: Paidós, 2003.

MOSCOVICl, S. Psicología de las minorías activas. Madrid: Morata, 1981.

MOSCOVICl, S. Social representations. Explorations in social psychology. Cambrige: Polity Press, 2000.

MOURA, R.; CLÓVIS, U. O que é periferia urbana. São Paulo: Brasiliense, 1996.

IBOPE. Comunicação e mídia: revelações sobre o mercado de telecomunicações. Disponível em: <http://www.ibope.com.br/giroibope/5edicao/comunicacao.htm>.

Acesso em: set. 2009.

PRYSTHON, A. Margens do mundo: a periferia nas teorias do contemporâneo. Revista Famecos, Porto Alegre, v. 1, n. 21, ago. 2003.

RÜDGER, F. Theodor Adorno e a critica à indústria cultural: comunicação e teoria crítica da sociedade. Porto Alegre: Edipucrs, 2004.

SÁNCHEZ, S. G. Revolução informacional: pontos de vista para o debate sobre a sociedade da informação. Transinformação, Campinas, v. 9, n. 1, p. 32-42, jan./abr. 1997.

SIBILIA, P. Show do eu: a intimidade como espetáculo. Rio de Janeiro: Nova Fronteira, 2008.

SOUZA, M. A. Movimentos sociais no Brasil contemporâneo: participação e possibilidade no contexto das práticas democráticas. In: VIII Congresso Luso-Afro Brasileiro de Ciências Sociais, 2003, Coimbra. 
Denise da Cruz Paim, Rodrigo de Oliveira Machado, Helena B. K. Scarparo, Adolfo Pizzinato

Luzes, câmera... Ação! No ar, a transformação midiática do conceito de periferia no conceito de comunidade

TAJFEL, $H$. Human groups and social categories. Cambridge: Cambridge University Press, 1981.

VIANNA, H. Central da Periferia - texto de apresentação. [2006]. Disponível em: <http://www.overmundo.com.br/perfis/hermanovianna>. Acesso em: 05 de set. 2009.

VILCHES, L. La televerdad - nuevas estratégias de mediación. Revista Telos, Madri: Fundesco, v. 1, n.43, 1996.

\section{Endereço para correspondência Denise da Cruz Paim}

Av. I piranga, 6681, Prédio 11, 9o andar, sala 930, CEP 90619-900, Porto Alegre - RS Endereço eletrônico: denise.cruz@itapemafm.com.br

\section{Rodrigo de Oliveira Machado}

Av. I piranga, 6681, Prédio 11, 9o andar, sala 930, CEP 90619-900, Porto Alegre - RS Endereço eletrônico: rodrigo.psicopuc@gmail.com

\section{Helena B. K. Scarparo}

Av. Ipiranga, 6681, Prédio 11, 9o andar, sala 929, CEP 90619-900, Porto Alegre, RS

Endereço eletrônico: helena.scarparo@pucrs.br

\section{Adolfo Pizzinato}

Av. I piranga, 6681, Prédio 11, 9o andar, sala 930, CEP 90619-900, Porto Alegre RS.

Endereço eletrônico: adolfo.pizzinato@pucrs.br

Recebido em: 07/11/2011

Aceito para publicação em: 01/04/2013

Acompanhamento do processo editorial: Deise Maria Leal Fernandes Mendes

\section{Notas}

1 Este artigo é originário da dissertação de mestrado de Denise da Cruz Paim realizada com o auxílio da Capes.

* Mestre em Psicologia Social pela Pontifícia Universidade Católica do Rio Grande do Sul.

** Mestrando em Psicologia Social pela Pontifícia Universidade Católica do Rio Grande do Sul.

*** Professora Doutora do Programa de Pós - Graduação em Psicologia da Pontifícia Universidade Católica do Rio Grande do Sul.

**** Professor Doutor do Programa de Pós - Graduação em Psicologia da Pontifícia Universidade Católica do Rio Grande do Sul.

2 O termo "tom" tem a vantagem de valer tanto para o escrito como para o oral. (Maingueneau, 2008)

${ }^{3}$ Neste quadro o apresentador/cantor escolhia uma menina da favela, através de carta, para passar o dia em sua companhia. Além de compras em shopping, elas ganhavam auxilio em dinheiro, cursos, móveis, eletrodomésticos, brinquedos e, em alguns casos, uma casa. Todos os prêmios eram oferecidos por patrocinadores

3 Criado em 1950 na Itália, pela International Quality Service I.Q.S., O Prêmio Qualidade foi instituido no Brasil em 1977, através da Associação Prêmio Qualidade Brasil. Ele presta homenagens a Artistas e Esportistas como forma de reconhecer e incentivar a qualidade da produção cultural brasileira. 